\title{
DAS SEPARAÇÕES À DESCOLONIZAÇÃO: UM COMPROMISSO DE LEITURA
}

\author{
Pedro Augusto Pereira Gonçalves ${ }^{1}$
}

RESUMO: O discurso filosófico ocidental da modernidade é marcado, em sua grande parte, pela separação completa entre os humanos e os animais. Immanuel Kant mobiliza um importante aparato argumentativo que, não apenas reafirma tal separação, mas estabelece a primeira definição filosófica, senão científica, do conceito de raça (BERNASCONI, 2001). Nosso interesse é apresentar a argumentação desenvolvida por Kant em alguns de seus textos mostrando o comprometimento dessa argumentação com: (i) a ideia de expropriação do mundo animal por meio do especismo, bem como (ii) a expansão colonial na medida em que "rebaixa" outras pessoas que não fazem parte da comunidade cosmopolita europeia de raça branca. Assim, é preciso entender a filosofia do esclarecimento vinculada ao compromisso com a supremacia branca (MILLS, $1997,2006)$ que ilustra a ontologia ocidental bem marcada pela dominação feita pelos brancos aos povos não europeus, bem como pela exploração do animal. Argumentamos, portanto, que o esforço pelas descolonizações precisa acontecer nas leituras contemporâneas da filosofia, área que muitas vezes marginaliza temas fundamentais nas concepções de seu próprio campo especulativo. 
PALAVRAS-CHAVE: Especismo; Racismo; Filosofia Moderna; Descolonização.

ABSTRACT: The Western philosophical discourse of modernity is framed, for its major part, for the complete separation between humans and animals. Immanuel Kant mobilizes an important argumentative apparatus which not only reasserts this separation, but also establishes the first philosophical definition, if not a scientific one, of the concept of race (BERNASCONI, 2001). My goal is to present the arguments developed by Kant in some of his texts showing its commitment with: (i) the idea of the animal world expropriation through speciesism, and (ii) the colonial expansion that "demeans" others who are not part of European cosmopolitan community of Whites. Thus, one must read Enlightenment philosophy as closely related to the commitment to white supremacy (MILLS, 1997, 2006) that illustrates the Western ontology framed by domination made by Whites to non-European peoples, as well as animal exploitation. I argue, therefore, that decolonization efforts must occur in contemporary readings on philosophy, area in which key issues in the conceptions of their own speculative field are often left aside.

KEYWORDS: Speciesism; Racism; Modern Philosophy; Decolonization. 
A era da inocência e da complacência terminou. Temos, portanto, que abandonar os sonhos de dominação.

Achille Mbembe

\section{INTRODUÇÃO}

Parte da filosofia ocidental apresenta-se como um desenrolar de teses no interior da noção histórica de progresso que mobiliza explicações e definições sobre várias questões que atormentaram os pensadores de seu tempo: a política como a origem e a necessidade do Estado e suas consequências morais, especulações em torno das obras de arte, as relações entre os humanos e a natureza, entre outras. É possível notar, ao selecionar alguns pensadores, um compromisso com certa ontologia que visa determinar, afinal de contas, o que somos nós, homens dotados de Razão que têm de manipular a natureza para melhor sobreviver neste meio que nos é hostil.

Os discursos filosóficos deste período estão consoantes ao nascimento e fundamentação do discurso científico, que passa a ganhar legitimidade na medida em que consegue entender os processos naturais para melhor explorá-los. Nesse investimento intelectual em favor dos progressos, a civilização moderna se lança aos mares e às florestas e em tudo que considera ser o novo mundo, medindo, investigando, dividindo, especulando e formulando leis e normas que assegurarão a consolidação do império europeu da Razão. É pela exploração dos recursos naturais, emocionais, existenciais e dos humanos - que sofreram as ações colonizatórias - que a Europa e, posteriormente, os Estados Unidos, são o que são hoje em dia, portanto. 
Assim sendo, cientes da história dessa construção que está assentada, na maioria das vezes, em ações violentas e expropriadoras tanto do continente Africano quanto das Américas, é deveras incômodo ir ao encontro dos textos filosóficos e notar que alguns deles estão em favor desse império que se erigiu de modo diverso dos já reconhecidos e consagrados discursos éticos da universalidade das gentes. Portanto, é preciso que se remontem as argumentações que foram mobilizadas nos textos e pensamentos da época a fim de que possamos dar um passo adiante dos colonizadores na medida em que tomamos conhecimento das fontes que nos fizeram quem somos e quais foram os meios utilizados para tanto. De forma alguma, portanto, este esforço está desvinculado de outro jeito de pensar a nossa existência e experiência enquanto povos múltiplos que vivemos nos territórios sul americanos. Territórios estes que foram colonizados e ainda são, através das dinâmicas neocoloniais de expropriação das mais diversas. Uma vez reconhecidas as óbvias e importantes contribuições do Iluminismo, seria a nós recomendado reafirmarmos a necessidade de uma "autodeterminação ontológica" (VIVEIROS DE CASTRO, 2015), outorgando-nos sentidos e consciências próprias para as nossas realidades de povos colonizados, expropriados e seviciados, mas que ainda resistimos e vivemos.

Acreditamos, portanto, que entrar em contato com os textos filosóficos e dele levantar as argumentações que exemplificam o panorama da colonização e como ela foi construída é deveras salutar neste esforço descolonizatório. Neste sentido, nosso texto remonta, ainda que brevemente, o panorama da separação que primeiro ocorreu entre humanos 
e animais e, posteriormente, apresentaremos a argumentação, também de forma breve, sobre o panorama da segunda distinção a partir da primeira; esta já entre os humanos, à luz do panorama das raças propostas por Immanuel Kant.

\section{A SEPARAÇÃO RADICAL DOS ANTIGOS COMPANHEIROS}

É desde Aristóteles que somos conscientes de nossa pretensa e completa separação dos animais, pois somente nós temos o dom da palavra. A linguagem é partilhada entre os seres humanos e, a partir dela, somos capazes de estabelecer comunidades éticas e desenvolver toda a sorte das capacidades da "dignidade exclusiva da natureza humana" - para nos lembrarmos de Lévi-Strauss (2013) - face às outras existências destituídas do dom da palavra. René Descartes se apoia nesta tese aristotélica para pôr em marcha todo o rigor distintivo de sua metafísica. Na gênese mesma da famosa distinção alma/ corpo está a recusa pela relação com os animais, uma vez que nos assemelhamos a eles apenas pela res extensa, ou seja, todos somos corpos. Porém, pelo advento da alma racional, que deve ser distinta do corpo justamente para estabelecer a primazia do humano sobre todas as coisas, é necessária tal distinção, pois de onde o homem poderia elevar-se e estabelecer seu império da Razão sobre as outras formas de existência? Justamente por seu pretenso diferencial ontológico: a Razão. Somente através dela e seus dois desdobramentos, a saber, linguagem e ação pelo conhecimento, é que somos capazes de nos reconhecer numa humanidade, participar de uma comunidade racional, legislar sobre o resto das existências e, 
sobretudo, atuar sobre elas a partir do nosso próprio julgo. Assim, conceber os animais apenas como máquinas, sem uma alma racional e incapazes de linguagem - incapazes de se relacionar inteligivelmente conosco, pois lhes falta a razão, é o próximo passo para elevar o homem sobre todas as coisas e fazer dele o senhor da natureza ${ }^{2}$. É dever dos seres que sobram se virar para se fazer entender, uma vez que

nunca poderiam usar palavras, nem outros sinais, compondo-os, como fazemos para declarar aos outros nossos pensamentos [...] e isso não testemunha apenas que os animais possuem menos razão que os homens, mas que não possuem nenhuma razão (DESCARTES, 1987, p. 6061).

Mas, entendemos que é com Immanuel Kant que o projeto de emancipação, elevação e primazia do homem sobre todas as coisas é estabelecido com vistas a determinar uma ideologia racional que visa colocar o homem no centro do mundo, através de sua tão conhecida revolução copernicana em filosofia.

Todo este processo de antropocentrismo está apoiado no projeto de disciplinarização humana pela educação que pretende, mais uma vez retomando as conceituações da gênese comum de natureza entre humanos e animais, cindir com os animais através do "algo a mais" que temos e eles não têm. Assim, Kant versa em um de seus últimos textos, a saber, Sobre a pedagogia, que "a disciplina transforma a animalidade em humanidade" (KANT, 1999, p. 12), uma vez que "os animais cumprem o seu destino espontaneamente e sem o saber. $\mathrm{O}$ homem, pelo contrário, é obrigado a tentar conseguir o seu 
fim [...]" (KANT, 1999, p. 18) para impedir, mais uma vez, "que a animalidade prejudique o caráter humano" (KANT, 1999, p. 25). E que fim é este? Justamente o de elevar-se para acima do mundo, transcender o conhecimento, se tornar o sujeito transcendental.

Aqui, se estabelece a cisão completa pelo esclarecimento, pela razão, e o conhecimento de suas potencialidades. Proceder de tal modo é, sem dúvida para Kant, em sua aclamada Aufklärung, "[...] tratar o homem, que é mais que uma máquina, conforme sua dignidade" (KANT, 2009, p. 413).

Pensar a filosofia como a possibilidade de afastar os homens de seu estado de natureza, inserindo-os em um reinado no qual eles podem legislar e cortar as cabeças das coisas que lhes causam ora necessidade, ora espanto, é, sem dúvida, um dos fundamentos mais sólidos da ideologia antropocêntrica que se faz etnocida e originária das maiores extinções em macha na atualidade, pois, tem em seu pano de fundo e como pedra de toque o lema brilhante e obsessivo do progresso, na medida em que se separam dos animais, na medida em que levantam "sua cabeça tão orgulhosamente acima dos seus antigos companheiros" (KANT, 2012, p. 6). Assim, lemos desta vez na Antropologia, e afetados pelo espanto da constatação especista,

que o ser humano possa ter o eu em sua representação, eleva-o infinitamente acima de todos os demais seres que vivem na terra. É por isso que ele é uma pessoa, e uma e mesma pessoa em virtude da unidade da consciência em todas as modificações que lhe possam suceder, ou seja, ele é, por sua posição e dignidade, um 
ser totalmente distinto das coisas, tais como os animais irracionais, aos quais pode mandar à vontade, porque sempre tem o eu no pensamento, mesmo quando ainda não possa expressá-lo, assim como todas as línguas têm de pensá-lo quando falam na primeira pessoa, ainda que não exprimam esse eu por meio de uma palavra especial. Pois essa faculdade (a saber, a de pensar) é o entendimento (KANT, 2006, p. 27).

A filosofia é considerada como uma das áreas de conhecimento mais estimadas, conferindo respostas às mais variadas perguntas na medida em que define o que é o homem, a liberdade, a melhor forma de se viver e todas as questões que nós, que lidamos com o discurso filosófico, lemos nas mais variadas obras. Porém, grande parte deste discurso opera por exclusão justamente na medida em que visa definir seus conceitos.

É com Kant, portanto, que o projeto iluminista e por primazia antropocêntrico se realiza, alijando completamente qualquer tipo de relação - a não ser, é claro, de dominação e exploração do mundo e das outras existências, certamente a pior consequência deste projeto emancipatório:

A equivocamente denominada revolução copernicana de Kant é, como se sabe, a origem oficial da concepção moderna de Homem (guardamos aqui a forma masculina) como poder constituinte, legislador autônomo e soberano da natureza, único ente capaz de elevar-se para além da ordem fenomenal da causalidade que seu próprio entendimento condiciona: o 'excepcionalismo humano' é um autêntico estado de exceção ontológico, fundado na separação autofundante entre Natureza e História. A 
tradução militante desse dispositivo mítico é a imagem prometeica do Homem conquistador da Natureza: o Homem como aquele ser que, emergindo do seu desamparo animal originário, perdeu-se do mundo apenas para melhor voltar a ele como seu senhor (DANOWSKI \& VIVEIROS DE CASTRO, 2014, p. 43).

Este "estado de exceção ontológico" de que nos falam Danowski e Viveiros de Castro condensa muito bem toda a argumentação que, desde Aristóteles, pretende separar o homem dos demais, formando todo o tipo de hierarquias, supremacias, julgamentos de superioridade, conhecimento suposto das relações verdadeiramente éticas, verdadeiramente estéticas, verdadeiramente políticas e verdadeiramente humanas. Só o que é conforme nós é que pode ser da nossa dignidade...

Desta separação ontológica abismal entre animalidade e humanidade, posta pela filosofia ocidental moderna e usada a contento pelos discursos científicos, surge, aos partidários da primeira condição, toda a forma de arbitrariedade, manipulação, uso indiscriminado, dominação, exploração, e outras formas de relação baseadas em intensas expropriações. Este "homem imperial" dispõe de diversos súditos: os outros homens que não lhe estão conforme seus ditames, objetos da natureza e seus recursos, bem como os animais. Nem precisamos nos alongar para dizer sobre as consequências deste império...

Essas formas de se relacionar com os outros são vistas por Giorgio Agamben como antropogênese: 
a ontologia ou filosofia primeira não é uma disciplina acadêmica inócua, mas uma operação em todo o sentido fundamental na qual se leva a cabo a antropogênese, $\mathrm{o}$ devir humano do vivente. A metafísica está presa desde o princípio nesta estratégia: ela diz respeito precisamente àquela metá que cumpre e custeia a superação da physis animal em direção da história humana. Esta superação não é um feito que se cumpriu de uma vez e para sempre, mas um evento sempre em curso, que decide a cada vez e a cada individuo acerca do humano e do animal, da natureza e da história, da vida e da morte. (AGAMBEN, 2006, p. 145).

Desta forma, a antropogênse demonstra a prática que é levada a cabo e que tem por sustentáculo os pressupostos que a tradição filosófica ocidental operacionalizou com vistas à própria separação metafísica e ontológica entre humanidade e animalidade ${ }^{3}$.

Fazendo eco de maneira bastante importante, Jacques Derrida diz de uma incapacidade dos humanos em reconhecer a alteridade animal, pois somente o autocentramento humano, incapaz de sair de si próprio ao talvez realizar, sobremaneira, o solipsismo cartesiano, reduziu de forma drástica as possibilidades de relação com vistas à conversa entre os demais seres existentes. Assim, escreve Derrida que

seus discursos [Kant, Heidegger, Lacan, Levinas] são fortes e profundos, mas neles tudo se passa como se eles nunca tivessem sido vistos, sobretudo não nus ${ }^{4}$, por um animal que se dirigisse a eles. Tudo se passa ao menos como se essa experiência perturbadora, supondo que ela lhes 
tenha ocorrido, não tivesse sido teoricamente registrada, precisamente lá onde eles faziam do animal um teorema, uma coisa vista, mas que não vê. A experiência do animal que vê, do animal que os observa, não a tomaram em consideração na arquitetura teórica ou filosófica de seus discursos. Em suma, eles tanto a negaram quanto desconheceram (DERRIDA, 2002, p. 36).

Em face de um princípio de razão um tanto quanto narcísico, e também conscientes de que a "aquisição de conhecimento nunca é inocente" (HARAWAY, 2011, p. 29), o que deveríamos levar em consideração, num esforço urgente de "partilhar o sofrimento" com os nossos companheiros nãohumanos, é primar por formas mais plurais de encarar e agir no mundo compartilhado. Numa verdadeira revolução política (ou melhor, e acertadamente, cosmopolítica ${ }^{5}$ ) jogar no time da razão sentida é uma opção pluralizante, uma vez que sua graça "é que ela está sempre aberta a uma cuidadosa reconsideração" (HARAWAY, 2011, p. 37). Este tipo de razão, que amplia e, de certa maneira, supera os limites da razão instrumental — uma vez que vai muito além da mera empatia, pois é carregada de afetos e movimento - é capaz de re-conhecer as vidas outras na medida em que tanto assume seus deméritos (como tornar tudo o que não é humano passível de ser matado) quanto visa às transformações que assegurem as vidas humanas ou não - a rigor, numa mudança de perspectiva para os que são matáveis.

Nada mais urgente num mundo compartilhado e às portas de mudanças geoclimáticas radicais pela iminência do Antropoceno. É preciso que se pare de matar e extinguir 
em nome do progresso, pois certamente e muito em breve encontraremos com sua verdadeira face que não deixa de ser a extensão da nossa mesma: a face que aniquila e extingue, usurpa e rouba recursos naturais, estéticos, políticos e ontológicos. Nós nos encontraremos, finalmente, com a face que nós mesmos produzimos e que muitos outros já encontram, infelizmente, há muito tempo.

Este tipo de miragem comprometida com as vidas outras, portanto, visa compartilhar agenciamentos, ou seja, "um novo entendimento de ontologia, epistemologia, ética e política tem de ser conquistado. Isso só será possível pela superação do antropocentrismo e do humanismo, a separação entre natureza e cultura" (MBEMBE, 2016, p. 26).

\section{A DIVISÃO NA UNIVERSALIDADE DA ESPÉCIE HUMANA}

De volta à Pedagogia de Kant, lemos: "e que grau de cultura a escrita já não supõe? - de tal modo que se poderia propor a invenção da escrita como começo do mundo com respeito à civilização" (KANT, 1999, p. 21). Nestas palavras, podemos encontrar a gênese do estatuto dos povos civilizados no interior de uma república das letras que comunicará entre si toda a cultura, contratos, convenções e leis - sejam elas jurídicas ou morais -, compondo, assim, uma ontologia específica do ocidente: o padrão eurocêntrico que se inscreve numa ideia de história como progresso do humano e que se fará presente para o resto dos povos senão pela ação colonizatória - esta, a seu turno, impondo-se através das diversas violências que soube fabricar. 
Quando Kant diz, desta vez na História Cosmopolita, que a história tem "um fio condutor a priori" (KANT, 1986, p. 23), nada mais significa dizer que a ordenação histórica conceberá a humanidade conforme uma linha evolutiva, que tem sua gênese no estado de natureza - exemplo maior são os povos "selvagens" - e, ao desenvolver as faculdades da razão, a espécie humana poderá apresentar homens de razão e cosmopolitas. Eles serão, portanto, o paradigma da Aufklärung: emancipados do estado de natureza animalesco e selvagem, produtores dos ordenamentos jurídicos e morais e, acima de tudo, produtores da cultura "superior" dos valores civilizatórios. Da manada aos conglomerados cosmopolitas, numa palavra.

Desse verdadeiro quadro pintado a mãos masculinas, brancas, heterossexuais e europeias, nasce toda uma concepção ideológica do progresso da história e da técnica, supremacia dos discursos científicos, planilhas orçamentárias e principalmente um modelo especifico de humanidade. Fora da moldura que enquadra esse cenário, tudo se encontra em estado de caos e selvageria. Portanto, a conclusão é óbvia: é necessário "converter" essas outras gentes à humanidade cosmopolita. A própria história nos mostra bem como isso se deu: missões jesuíticas, sociedades disciplinares, fabricações de corpos e espíritos, supressão de outras manifestações religiosas e culturais, divisão do mundo em parcelas de desenvolvimento, dentre tantas outras formas que devem ser traduzidas como colonização; esta que carrega consigo etnocídios, genocídios, epistemicídios e outras ações aniquiladoras. Se o bom senso é a coisa mais bem distribuída no mundo, ele não está isento das pegadas profundas e expropriadoras que deixa através de 
sua marcha avassaladora nos terrenos da diferença. Imagem melhor deste paradigma nos é fornecida por Kant, desta vez no Segundo artigo definitivo no interior de sua Paz Perpétua:

Assim como olhamos com profundo desprezo o apego dos selvagens à sua liberdade sem lei de preferir brigar incessantemente a submeter-se a uma coerção legal a ser construída por eles mesmos, por conseguinte preferindo a liberdade insensata à racional, e os consideramos estado bruto, grosseria e degradação animalesca da humanidade, deveríamos pensar que povos civilizados (cada um unido em um Estado) teriam de apressar-se a sair o quanto antes de um estado tão abjeto (Kant, 2010, p. 31-32).

Há, portanto, diferentes classes (raças) ${ }^{6}$ de homens no interior da universalidade que tem seu limite justamente na espécie humana. Para além dela, há diferenças que se justificam naquele fio condutor da história que legitima a própria diferença e "degrada" quem não é suficientemente esclarecido e evoluído. O efeito do panorama das distinções raciais que tem por horizonte operacional o racismo é, conforme Aníbal Quijano, um dos principais centros da modernidade colonial eurocêntrica, uma vez que forja

uma concepção de humanidade segundo a qual a população do mundo se diferenciava em inferiores e superiores, irracionais e racionais, primitivos e civilizados, tradicionais e modernos (QUIJANO, 2010, p. 86). 
Logo, a parcela de pessoas esclarecidas e superiores se contrapõe, assim, a todas as outras sub-pessoas [Untermenschen] (MILLS, 2005) e, muito mais além, aos animais e vidas nãohumanas. É deveras importante, assim, não marginalizar ou tentar esconder as passagens especistas, misóginas, sexistas, xenófobas e racistas presentes no decorrer quase unânime da tradição filosófica e também em Kant, que chega a formular que

Todas as raças serão erradicadas (americanos e negros não podem governar a si mesmos. Servem, portanto, apenas como escravos), menos a dos brancos [os quais] contêm todos os móbeis da natureza em afetos e paixões, todos os talentos, todas as disposições à cultura e civilização, e podem assim tanto obedecer quanto dominar [sendo] os únicos que sempre progridem à perfeição (KANT, 1923, p. 878).

O que aparece na argumentação kantiana na Paz Perpétua e se radicaliza na passagem supracitada deve ser entendido como uma separação definitiva entre o centro do mundo (Europa) e a sua periferia (Não-Europa): "A Europa é civilizada. A Não-Europa é primitiva. O sujeito racional é Europeu. A Não-Europa é objeto de conhecimento" (QUIJANO, 2010, p. 111-112). A consequência desta ideologia que está em serviço da gênese da dominação e expansão capitalista é pensar nas sociedades ditas atrasadas e selvagens justamente por não terem desenvolvido a escrita - tal como Kant entende ser a origem dos povos civilizados - desconsiderando sua história e modos de existir imensamente profundos e autóctones. 
Entretanto, “a não ser por racismo, não há porque julgá-los incapazes de refletir sobre sua própria experiência e de dar a seus problemas as soluções apropriadas" (CLASTRES, 2013, p. 39) [Grifo nosso].

O filósofo jamaicano Charles Mills pensa que a produção do conhecimento filosófico ocidental é mais bem entendida como "supremacia branca" que está carregada de privilégios e atua em dimensões econômicas, culturais, cognitivomorais, somáticas e, a rigor, metafísicas (MILLS, 2006). Essa supremacia branca quase sempre não se dá conta de que sua posição é estritamente política e, em última análise, um modelo de dominação. A filosofia, sendo um dos estudos das humanidades mais brancos, segundo o autor, permanece intocada pelas questões em torno da diversidade cultural e étnica. É preciso, portanto, fazer com a filosofia política (branca) o que os estudos feministas fazem com os estudos de ética e política ao combaterem o machismo e o patriarcado, por exemplo. O que Mills está defendendo, a rigor, é o

reconhecimento de que o racismo (ou, como eu entendo, a supremacia branca global) é por si mesmo um sistema político, uma estrutura de poder particular de regras formais e informais, privilégios socioeconômicos e normas de distribuição diferenciadas das riquezas materiais e oportunidades, benefícios e obrigações, direitos e deveres (MILLS, 1997, p. 3).

O racismo que foi produzido pela ideia da supremacia branca e que foi levado às últimas consequências pelas maiores figuras da modernidade tem por fundamentação, em primeiro lugar, a literatura voltada às ciências naturais. 
O desenvolvimento delas para melhor entender os recursos naturais com o intuito de manejá-los conforme as necessidades expansionistas do capitalismo faz com que as ciências passem a ter certa autoridade do seu discurso cada vez mais efetivo na modernidade. Portanto, é notório que seja nesse discurso que se encontre a fundamentação e o ponto de partida para que a filosofia possa manejar o conceito de raça. Assim, "a genealogia do racismo no Ocidente moderno é inseparável do surgimento da categoria classificatória da raça na história natural" (WEST, 2002, p. 99). Então, quando Kant diz ser a razão, suas faculdades e seu papel ordenador, quem determina os discursos em torno de uma especulação sobre a história da natureza (KANT, 2013), a raça - que para Mbembe é uma "ficção útil, uma construção fantasista e uma projeção ideológica" (MBEMBE, 2014, p. 27) e, para Quijano, "o mais eficaz e durável instrumento de dominação social universal" (QUIJANO, 2005, p. 118) - finalmente ganha cidadania filosófica, pois participa da teleologia que fundamenta a própria natureza e sua história.

Ora, em um mundo em que as pessoas ainda sofrem intensamente os efeitos das produções racistas que visam as diminuir para colonizar seus corpos, mentes, espíritos e territórios com vistas à expansão dos próprios algozes colonizadores, é urgente retornar aos textos canônicos e entender as consequências de suas vibrações nos povos outros:

o que o conceito de modernidade faz é esconder, de forma engenhosa, a importância que a espacialidade tem para a produção deste discurso. É por isso que, 
na maioria das vezes, aqueles que adotam o discurso da modernidade tendem a adotar uma perspectiva universalista que elimina a importância da localização geopolítica (MALDONADO-TORRES, 2010, p. 411).

Nesse sentido, é primaz prestarmos atenção às tentativas e esforços que visam descolonizar e reabilitar tantos séculos de silêncios impostos em detrimento à voz unificadora e enrijecedora do Ocidente. A importante e didática, mas não suficiente, leitura estrutural do texto filosófico precisa ser reformulada, no sentido de permitir que se entendam os contextos de nascimento e os propósitos da própria escrita.

Sobre o lugar da escrita filosófica que, de certo modo, ao especular sobre a raça produz, posteriormente, o racismo, seria interessante considerar a "análise de discurso crítica" proposta por Teun A. van Dijk. O autor formula que o racismo é ensinado através de várias formas de discurso:

Este processo de aprendizagem é, em grande medida, discursivo, e se baseia nas conversas e nos relatos de todos os dias, nos livros, na literatura, nos filmes, nas notícias, nos editoriais, nos programas de televisão, nos estudos científicos, etecetera. [...] Em outras palavras, a maior parte dos membros dos grupos dominantes aprendem o racismo através dos discursos de uma ampla variedade de fatos comunicativos (VAN DIJK, 2007, p. 25) [Grifos do autor].

Assim sendo, a filosofia também pode ser considerada como uma fonte de aprendizagem do racismo, ainda que algumas pessoas reproduzam o mito da democracia racial ou 
achem um absurdo que exista racismo nos dias de hoje, bem como outras formas de violência que ainda se proliferam. Entretanto, se ainda existem pessoas que padecem dia após dia com os efeitos nefastos do racismo - chegando mesmo a perder suas vidas em decorrência deles - e se alguns textos de filosofia que contêm postulados racistas ainda são estudados sem que se considere a temática, é bastante significativo que entendamos o que o discurso é capaz de produzir. Assim, também consideramos de extrema importância que se entenda os lugares da geopolítica $a^{7}$ nos textos, dando um salto maior ainda do que pode fazer a leitura estrutural.

No tocante pelo menos, mas não só, ao racismo - que consideramos ser um dos problemas mais fundamentais da sociedade brasileira atual e que tem por fundamento certos discursos filosóficos, como, aliás, acontece com a maioria dos saberes - cumprir-se-á a prestação de contas com um modelo de fazer e ler filosofia que precisa ser modificado e transformado num verdadeiro esforço de "descolonização metafísica" (VALENTIM, 2015). Um modelo que pare de (re) produzir exclusões das mais cruéis e que tantas vezes está maquiado com a intenção de aparecer como um discurso superior, limpo e livre de problemas reais.

\section{CONCLUSÃO}

Não sobrará muito a dizer após considerarmos a importância das discussões e revisões, mas sem revisionismo ou revanchismo, dos textos filosóficos que acabam por colaborar com visões excludentes e violentas. Urgente é tentar reparar 
o que for possível, reconstituir a vida e as relações nossas com as outras formas de existência que nunca se opuseram pela relação - a não ser as dadas pela violência - primar pela conversa com diálogo, pela convivência e pelas formas plurais, democráticas e de direitos fundamentais conquistados e que não podem ser perdidos, de forma alguma. Não temos alternativa, a não ser que sejamos coniventes com mais anos e anos, e certamente séculos - se o mundo ainda resistir, digase de passagem, com mais violências, expropriações e redução da vida que, por mais que se tente condicioná-la e reduzi-la, ainda insiste em vibrar e a se expandir.

\section{NOTAS}

${ }^{1}$ Mestrando (CAPES) em Filosofia pela Universidade Federal do Paraná (UFPR) e aluno integrante do SPECIES - Núcleo de Antropologia Especulativa da UFPR. E-mail: pgon.mt@gmail.com.

${ }^{2}$ Donna Haraway encara essa primazia do humano que, por meio de sua razão hierárquica, lega a objetificação e opressão que subjuga as vidas nãohumanas. Segundo a filósofa, este panorama de "cálculos complacentes se inspiram no dualismo primário que separa de um lado o corpo, de outro lado a mente. Esse dualismo deveria ter acabado há muito tempo diante das críticas feministas e tantas outras, mas o fantástico sistema binário mente/corpo demonstrou uma notável resiliência. Creio que a incapacidade, ou melhor, a recusa de encarar os animais é uma das razões" (HARAWAY, 2011, p. 31).

3 Essa "antropogênese" também é capaz de abarcar a distinção entre natureza e cultura se a pensarmos como origem da clivagem que distingue humanos entre si. Nas palavras de Lévi-Strauss, "os antigos gregos e os antigos chineses qualificavam os povos que não participavam de sua cultura com termos que nós traduzimos como 'bárbaro' e que, etimologicamente, 
parecem, nos dois casos, evocar o gorjeio dos pássaros. Portanto, eles os remetiam para os lados da animalidade; e o termo 'selvagem', que por muito tempo empregamos e que significa 'da selva', evoca também um gênero de vida animal, por oposição à cultura humana. Recusamos, assim, admitir o próprio fato da diversidade cultural: preferimos repelir para fora da cultura, para a natureza - como mostra o termo alemão 'Naturvölker' - tudo o que se afasta das normas sob as quais vivemos" (Lévi-Strauss, 2012, p. 79).

${ }^{4}$ Essa "experiência perturbadora" deve ser entendida no interior do texto de Derrida a partir da visão animal - animal este que é nu - que consegue vislumbrar o homem que já foi nu e sua "essência" que está escondida por este verniz filosófico/cultural/ontológico.

5 Perspectiva que, grosso modo, concebe animais, humanos, seres espirituais, seres naturais e outros seres como humanos para si mesmos e, portanto, dotados de agência política plena e capazes de exercê-la resolutamente e em relação (às vezes pacífica, mas muitas outras vezes não) com as outras comunidades de humanos outros, como no exemplo do pensamento ameríndio estudado por certa tradição etnográfica brasileira: “quando um índio interage com um existente de 'outra espécie' - o que, repetimos, inclui os membros de outros coletivos que nós chamaríamos de 'humanos' -, ele sabe que está tratando com uma entidade que é humana em seu próprio departamento. Assim se dá então que toda interação transespecífica nos mundos ameríndios é uma intriga internacional, uma negociação diplomática ou uma operação de guerra que deve ser conduzida com a máxima circunspecção" (DANOSWKI \& VIVEIROS DE CASTRO, 2014, p. 96).

${ }^{6}$ Para uma argumentação mais detalhada sobre o panorama das raças e do racismo em Kant, ver Eze (1997), Bernasconi (2001, 2002, 2003), Mills (2005), Gonçalves (2015), entre outros.

7 Sobre a geopolítica, ver a discussão proposta pelos autores latinoamericanos que pensam e escrevem sobre a descolonização, em especial, Maldonado-Torres (2010). 


\section{REFERÊNCIAS}

AGAMBEN, G. Lo abierto. $1^{\text {a }}$ edição. Tradução Flávia Costa e Edgardo Flávio. Buenos Aires: Adriana Hidalgo, 2006.

BERNASCONI, R. Who invented the concept of race? Kant's role in the Enlightenment construction of race. In: BERNASCONI, R. (org) Race. Oxford: Blackwell Publishers, 2011.

BERNASCONI, R. Kant as an unfamiliar source of racism. In: WARD, J. e LOTT, T. (org). Philosophers on race: critical essays. EUA: Blackwell Publishers, 2002. p. 145-166.

BERNASCONI, R. Will the real Kant please stand up. In: Radical Philosophy. no.117. 2003. p. 13-22.

CLASTRES, P. Sociedade contra o Estado. Pesquisas de Antropologia Política. Tradução Theo Santiago. Edição Cosac Naify Portátil. São Paulo: 2013.

DANOSWKI, D., VIVEIROS DE CASTRO, E. Há mundo por vir? Ensaio sobre os medos e os fins. Florianópolis: Cultura e Barbárie, Instituto Socioambiental, 2014.

DERRIDA, J. O animal que logo sou. Tradução Fábio Landa. São Paulo: Editora Unesp, 2002.

DESCARTES, R. Discurso do método. Tradução J. Guinsburg e Bento Prado Júnior. Coleção Os Pensadores. São Paulo: Nova Cultural, 1987. 
EZE, E. C. The color of Reason: the ideia of "race" in Kant's Anthopology. In: Postcolonial African Philosohy. EUA/RU: Blackwell Publishers, 1997. p. 103-131.

GONÇALVES, P. Universalidade exclusiva: o racismo em Immanuel Kant. Monografia de Conclusão de Curso em Filosofia. Curitiba: Universidade Federal do Paraná, 2015.

HARAWAY, D. A partilha do sofrimento. In: Horizontes Antropológicos. Ano 17, n 35. Porto Alegre: UFRGS, 2011. p. 2764.

KANT, I. À paz perpétua. Tradução e prefácio de Marco Zingano. Porto Alegre: L\&PM, 2010.

KANT, I. Resposta à questão: O que é o esclarecimento. Tradução Vinícius de Figueiredo. In: Antologia de textos filosóficos. Curitiba: SEED/PR, 2009. p. 406-414.

KANT, I. Sobre a pedagogia. Tradução Francisco Cock Fontanella. $2^{a}$ edição revisada. Piracicaba: Editora Unimep, 1999.

KANT, I. Resenha do escrito de Moscati: Da diferença corpórea essencial entre a estrutura dos animais e dos homens. Tradução Alexandre Hahn. In: Kant e-Prints. Série2, v. 7, n 2. Campinas: 2012. p. 4-6.

KANT, I. Antropologia de um ponto de vista pragmático. Tradução Clália Aparecida Martins. São Paulo: Iluminuras, 2006.

KANT, I. Ideia de uma história universal de um ponto de vista cosmopolita. Tradução Ricardo Terra e Rodrigo Navaes. Coleção 
Elogio da Filosofia. Edição bilíngue português/alemão. São Paulo: Editora Brasiliense, 1986.

KANT, I. Gesammelte Schriften, Band XV: Handschriftlicher Nachlass, II-2: Anthropologie. Herausgegeben von der Königlich Preussischen Akademie der Wissenschaften. Berlin, Leipzig: Walter de Gruyter, 1923.

KANT, I. Sobre o uso de princípios teleológicos na filosofia. Tradução, notas e comentários de Marcio Pires. In: Trans/Form/ Ação. v. 36, nº 1. Marília: Jan./Abril, 2013. p. 211-238.

LÉVI-STRAUSS, C. A antropologia diante dos problemas do mundo moderno. Tradução Rosa Freire d'Aguiar. São Paulo: Companhia das Letras, 2012.

LÉVI-STRAUSS, C. Antropologia estrutural dois. Tradução Beatriz Perrone-Moisés. São Paulo: Cosac Naify, 2013.

MALDONADO-TORRES, N. A topologia do ser e a geopolítica do conhecimento. Modernidade, império e colonialidade. In: SANTOS, B. S.; MENEZES, M. P. (Org.). Epistemologia do Sul. $1^{\text {a }}$ edição, 2a reimpressão. São Paulo: Cortez Editora, 2010. p. 396443.

MBEMBE, A. Crítica da razão negra. Tradução Marta Lança. Lisboa: Antígona, 2014.

MBEMBE, A. Decolonizing knowledge and the question of the archive. Texto de conferência. Johanesburgo: Universidade de Witwatersrand, 2016. p. 1-29. 
MILLS, C. W. The racial contract. EUA: Cornell University Press, 1997.

MILLS, C. W. "Kant's Untermenschen". In: VALLS, A. (ed.), Race and Racism in Modern Philosophy. London: Cornell University Press, 2005. p. 1-34

MILLS, C. W. White supremacy. In: LOTT, Tommy and PITTMAN, John (org). Blackwell Companions to Philosophy: A companion to African-American Philosophy. USA: Blackwell Publishing, 2006. p. 269-281.

QUIJANO, A. Colonialidade do Poder, Eurocentrismo e América Latina. In: Colonialidade do poder: Eurocentrismo e Ciências Sociais. Buenos Aires: CLACSO, 2005. p. 117-142.

QUIJANO, A. Colonialidade do poder e classificação social. In: SANTOS, B. S.; MENEZES, M. P. (Org.). Epistemologias do Sul. $1^{\text {a }}$ edição, 2a reimpressão. São Paulo: Cortez Editora, 2010. p. 84130.

VALENTIM, M. A. Descolonização metafísica. Esboço de manifesto contra-filosófico. Texto de comunicação apresentado no II COPENE SUL. Curitiba, 2015. p. 1-15.

VAN DIJK, T. A. Racismo y discurso en América Latina: una introducción. In: Racismo y discurso em América Latina. Barcelona: Biblioteca Iberoamericana de Pensamiento, Gedisa Editorial, 2007. p. 21-34. 
VIVEIROS DE CASTRO, E. Metafísicas canibais. Elementos de uma antropologia pós-estrutural. São Paulo: Cosac Naify, 2015.

WEST, C. A genealogy of modern racism. In: ESSED, P., GOLDBERG, D. (org) Race Critical Theories. New Jersey: Blackwell Publishers, 2002. p. 90-112. 